\title{
Short-term solutions to squeezing ground at Agnew Gold Mine, Western Australia
}

\author{
CE Woolley Gold Fields Australia Pty Ltd, Australia \\ P Andrews Gold Fields Australia Pty Ltd, Australia
}

\begin{abstract}
The Waroonga Underground Complex (Agnew Gold Mine) utilises the longhole open stoping method to extract ore from a quartz breccia zone. The Lode 1 ore zone dips west at approximately $65^{\circ}$ and sits between a geological hanging wall (HW) made up of a sandstone unit and geological footwall (FW) made up of altered sandstone/ultramafic rock units. During 2014, Lode 1 transitioned from a V-shaped mining front to an $M$, or inverted double $V$, mining front. No deviation from the existing ground conditions was observed during transition from $V$ to $M$ front.

When production began at 1,180 m below surface reduced level (RL) (Level 1), a higher degree of deformation was observed in the FW and HW shoulder of this level and the four levels below (Levels 2-5) than had been previously seen.

This study outlines the monitoring, modelling, testwork and short-term strategies put in place to ensure that potential impacts to personnel, safety and production are minimised while longer-term solutions to squeezing ground are examined. Monitoring includes extensometer pins installed over two levels, with profile survey points also included in the lowermost level. Photographic monitoring stations are established in all active development/production levels.

The initial numerical modelling undertaken included 2-dimensional finite element and kinematic analysis to ensure that the ground support used would achieve the required Factor of Safety (FS).

Preliminary observations indicate that regional faults in the ore zone play a significant part in level of FW deterioration with the majority of squeezing occurring between the 'Thresher' fault and 'Sandbar' fold in the northern part of the ore drives. Testwork commissioned on core samples from the affected ore drives focused on mineralogy testing. Alteration mineral type and abundance in FW rock units are hypothesised to be influencing squeezing behaviour.

Where deformation has occurred in levels ahead of stoping, they have been signed off and rehabilitation is conducted just prior to production requirements. It is believed that further modelling and trials of ground support systems/elements, possibly in conjunction with changes to extraction sequence, are required to mitigate squeezing conditions in the longer term, with ground support being varied according to likelihood of squeezing. However, it is believed that the current strategy of monitoring and signing off affected areas before just-in-time rehabilitation is an adequate short-term solution.
\end{abstract}

\section{Introduction}

Squeezing ground conditions have been defined as those where deformation will reach tens of centimetres within the life span of the excavation (Potvin \& Hadjigeorgiou 2008). It is commonly accepted that where squeezing ground conditions exist it is not practical to halt deformation (Hadjigeorgiou et al. 2013) and work should focus instead on controlling ground movement.

When dealing with squeezing ground, it is particularly important that the challenges associated with mining under these conditions be fully appreciated (Mercier-Langvin \& Wilson 2013), and a proper understanding of the rock mass response to mining be established. 
This study deals with the unexpected change in ground conditions from minor to extreme encountered over the five deepest levels of Lode 1 at the Waroonga Underground Complex; in particular, the data collection techniques, results, observations and short-term solutions put in place to mitigate impacts to safety and production.

\section{Background}

Agnew Gold Mine is situated on the western limb of the Lawlers anticline within the northern part of the Norseman-Wiluna greenstone belt. The Waroonga underground complex lies within the Scotty Creek Sandstone formation, at the margin of the Sandstone and Ultramafic conglomerate boundary.

The Waroonga Underground Complex utilises the longhole open stoping method to extract ore from four separate lodes; however, this study will deal with Lode 1 only. Lode 1 is a quartz breccia ore zone, of between 2 and $7 \mathrm{~m}$ width, dipping at $\approx 65^{\circ}$ to the west creating sandstone $\mathrm{HW}$ and altered sandstone/ultramafic FW in ore drives and stopes. Ore drive development is commonly completed about six months before stoping begins to allow time for grade control drilling and geological model updates to be completed.

All waste development is situated in the sandstone unit (SKG). Altered sandstone (SKgU) and ultramafic (SkU3) units are only encountered in ore drives and squeezing ground is associated solely with these units/areas. Dominant bedding in sandstone and altered sandstone/ultramafic units is orientated parallel to ore drives, which is acknowledged to be a poor orientation, which exacerbates squeezing conditions (Hadjigeorgiou 2013).

Historically Lode 1 has experienced problems associated with squeezing ground, with Mercier-Langevin and Hadjigeorgiou (2011) placing the operation within the minor to severe squeezing range of the hard rock squeezing ground index (Figure 1). No significant deformation/squeezing ground has been observed during mining between 2008 and 2013.

Primary ground support in ore drives consists of $60 \mathrm{~mm}$ of high toughness fibrecrete (FC) applied from the FW floor to $\approx 2.5 \mathrm{~m}$ above HW floor, pinned with a combination of $2.4 \mathrm{~m}$ resin bolts and friction stabilisers. Secondary support consists of six $6 \mathrm{~m}$ and three $8 \mathrm{~m}$ cable bolts per cut installed on a four cut lag with the development face (Figure 2).
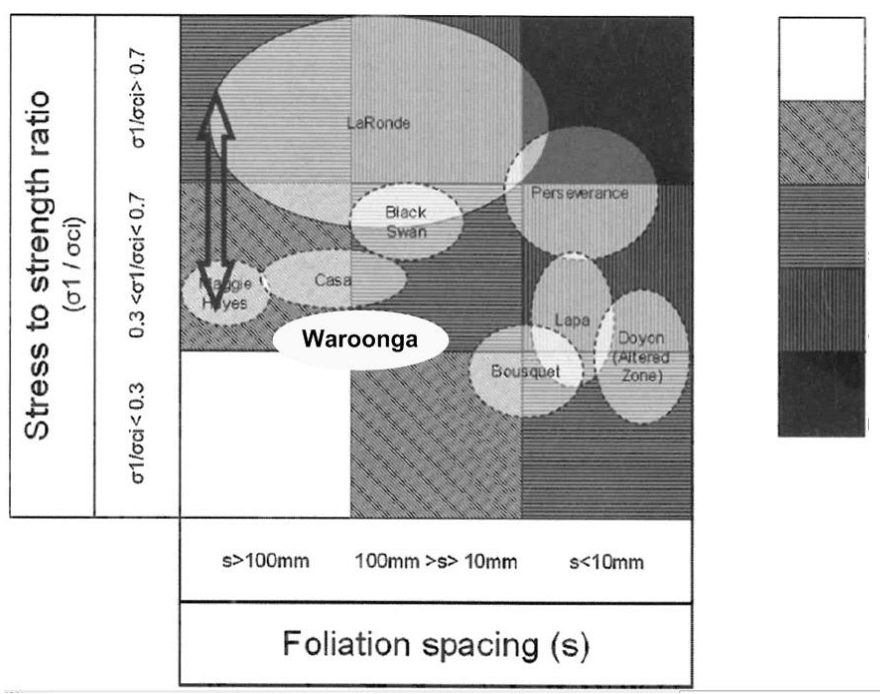

No Squeezing (strain <1\%)

Minor Squeezing ( $1 \%<$ strain $<2.5 \%)$

Severe Squeezing $(2.5 \%<$ strain $<5 \%)$

Very Severe Squeezing ( $5 \%<$ strain $<10 \%)$

Extreme Squeezing (strain $>10 \%$ )

Figure 1 Squeezing potential of Waroonga underground complex after Mercier-Langevin and Hadjigeorgiou (2011)

During 2014, Lode 1 transitioned from a $V$ mining front to an $M$, or inverted double $V$, mining front (Figure 3); no deviation from expected ground conditions was observed during transition. When 
development began in the lower levels (>1,180 m below surface $\mathrm{RL}$ ) a higher degree of deformation was noted in the FW combined with deterioration in the HW shoulder, than observed during recent history, progressing to significant floor heave and FW deterioration as stoping continued.

When stoping began in Level 1, development was complete in Levels 2 and 3 and on-going in Level 4; development had not yet begun in Level 5. To date, squeezing conditions have been observed during development and production phases of the lowest five levels of Lode 1 at a depth range of 1,180-1,260 m below surface.

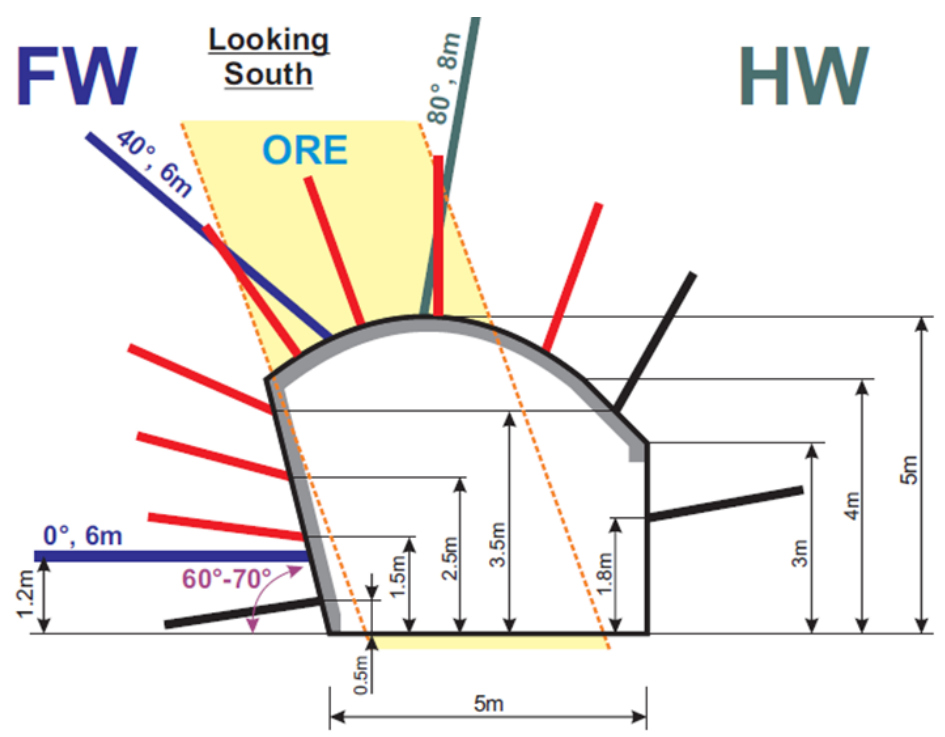

NOTES

Fibrecrete FW side down to floor

Fibrecrete HW side down to $2.5 \mathrm{~m}$ as shown

Minimum thickness of fibrecrete is $60 \mathrm{~mm}$

Overlap fibrecrete with previous cut by $0.2 \mathrm{~m}$

Spacing between rings $=1.4 \mathrm{~m}$

Spacing between bolts within a ring - as shown

ALLResin bolts: Point anchers

- If required, install additional spot bolts to ground conditions

Cablebolts may lag face by up to 4 cuts

-Plate and tension all cablebolts - BOTH STRANDS

\section{LEGEND}

Resin bolts $2.4 \mathrm{~m}$ (Fero Spring T20 bolts)

Fibrecrete $60 \mathrm{~mm}$ thickness, $500 \mathrm{~J}$ min toughness

$8 \mathrm{~m}$ TWIN strand cablebolts

$6 \mathrm{~m}$ TWIN strand cablebolts

- Dome Washer Bolts $2.4 \mathrm{~m}$

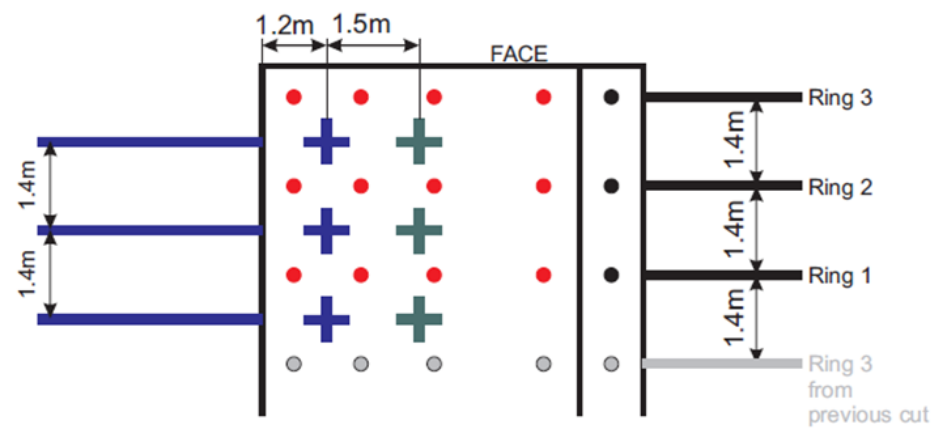

QUANTITY PER $4.2 \mathrm{~m}$ CUT

$5.0 \mathrm{~m}^{3}$ of fibrecrete

$21 \times 2.4 \mathrm{~m}$ resin bolts

$9 \times 2.4 \mathrm{~m}$ Dome Washer Bolts

$60 \mathrm{~m}$ TWIN strand cablebolts

\begin{tabular}{|c|c|}
\hline 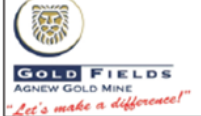 & $\begin{array}{l}\text { AGMC } \\
\text { Waroonga } \\
\text { Underground }\end{array}$ \\
\hline
\end{tabular}

Ore Drive Ground Support - Lode 1

\begin{tabular}{|c|l|l}
\hline $\begin{array}{c}\text { Sr. Geotechnical } \\
\text { Engineer }\end{array}$ & & \\
\hline $\begin{array}{c}\text { Underground } \\
\text { Manager }\end{array}$ & & \\
\hline
\end{tabular}

Figure 2 Lode 1 ore drive ground support

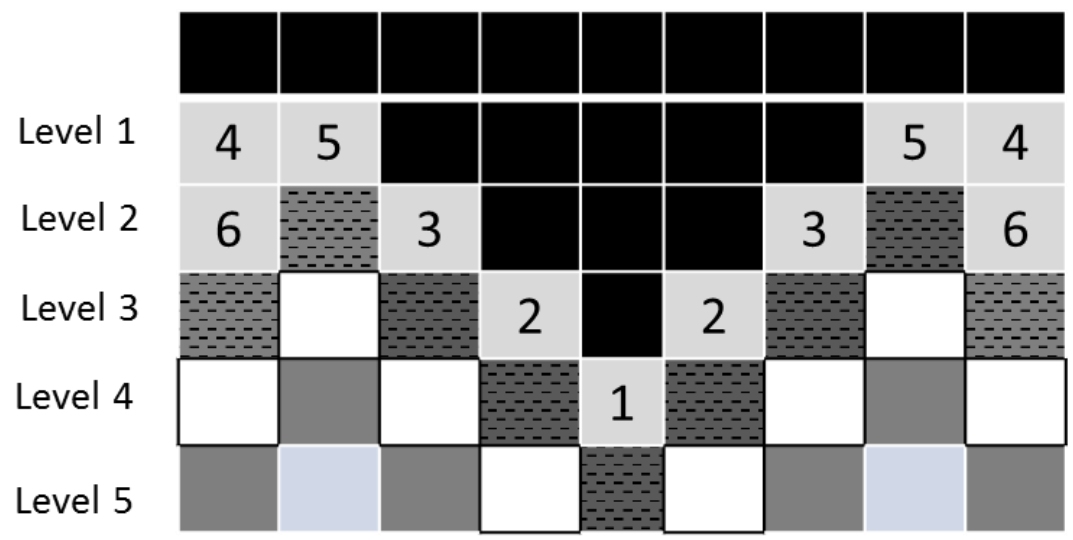

Figure $3 \quad \mathrm{M}$ front schematic 


\section{Observations and data collection}

Development of Level 1 progressed as expected with minor squeezing conditions observed. As stoping began some cracking was observed in FW fibrecrete, with evidence of resin and cable bolts in area taking load. Initial signs of deterioration were also observed in Levels 2 and 3 and lower down as stoping progressed.

Deterioration in ore drives where stoping had not yet begun was unusual in Lode 1 . Once it was observed FW support was increased in affected areas, extensometer pins installed, and photo monitoring stations established. As ore drive ground condition deteriorated laboratory tests were commissioned and numerical modelling undertaken.

\subsection{Observations}

In Level 1, where deformation was observed only after stoping began on the level, squeezing progressed quickly and rehabilitation was required after each panel of the central ore drive was extracted. Minor rehabilitation, including mesh over cracking FC, was required to access northern stopes. More significant rehabilitation in north ore drive was undertaken when the final panel in this central area was extracted. The intersection and FW had to be stripped in order to maintain access. No significant deformation was observed in southern ore drive.

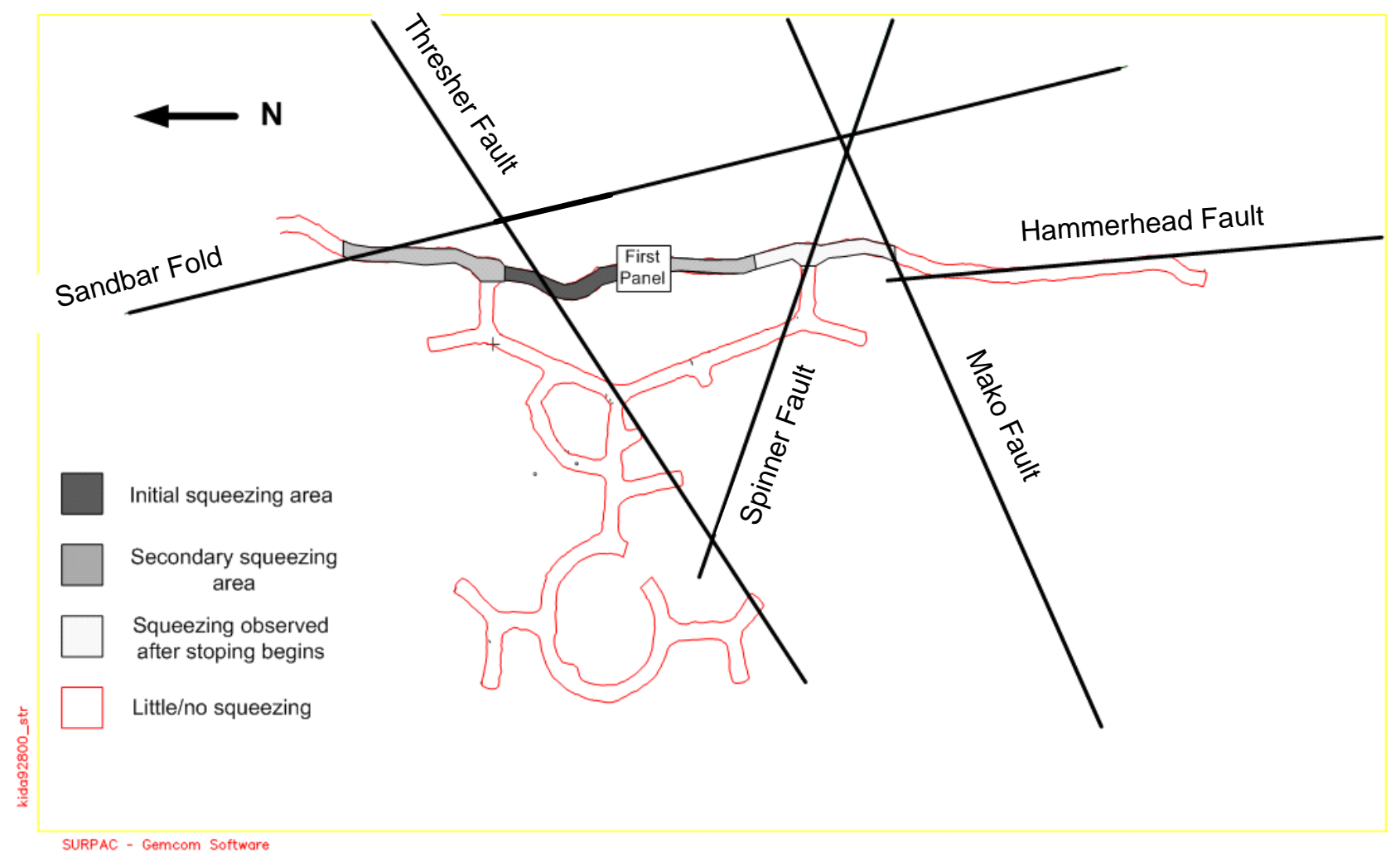

Figure 4 Squeezing areas in Lode 1 ore drives

Where squeezing conditions were observed in ore drives prior to stoping (Levels 2, 3, 4 and 5), the progression of squeezing/deteriorating ground appears to follow a noticeable pattern (Figure 4):

- Stage 1:

Deterioration occurs first in the central ore drive around the Thresher fault zone. On the FW cracking is observed in FC, with rockbolt plates taking load in this area. Initial signs of deformation in the HW shoulder may also be observed; noticeable deterioration to HW shoulder at this stage has predominantly been seen in lower ore drives (Levels 4 and 5 ). 
- Stage 2:

Deterioration continues around the Thresher fault zone; FW bulging becomes noticeable and rockbolt plates may fail in this area; initial indicators of floor heave are observed. Bulging will also become noticeable in the HW shoulder; bolts begin to fail in backs.

Stage 1 style deterioration will be observed in the north ore drive up to the Sandbar fold and in the remainder of the central ore drive. No deterioration is observed in south ore drive.

- Stage 3:

Significant floor heave and FW bulging is seen around Thresher fault zone, and more than $20 \%$ of ground support in area is compromised; failing rockbolts, significant FC cracking and failure. HW shoulder/backs may fail if not meshed, and slabbing is observed on the sidewall. Stage 2 style deformation is observed in the north and remainder of central ore drive.

- Stage 4:

FW bulging will extend into north and central ore drive; floor heave will be observed but not to the extent of that around the Thresher fault zone. Minor buckling on bedding and deterioration of HW sidewalls and bulging of shoulder/backs noted.

- Stage 5:

Ground support in northern pillar of access-ore drive intersections begins to show significant signs of deterioration. Jumbo probing will show a broken ground depth of more than $1.5 \mathrm{~m}$. Area will be designated 'No Entry'; failure of north intersection will be observed (Figure 5). Severe slabbing from HW sidewall and failure of backs will be observed in north ore drive.

In Levels 2 and 3 stoping began after stage 3 deformation had been observed and quickly escalated with rehabilitation required after each central stoping panel and to access northern stopes. The intersection was stripped and re-supported.

In Level 5, Stage 1 deformation was observed during development for the first time; it took six months from first ore drive development to the area around Thresher fault zone being designated as 'No Entry'.

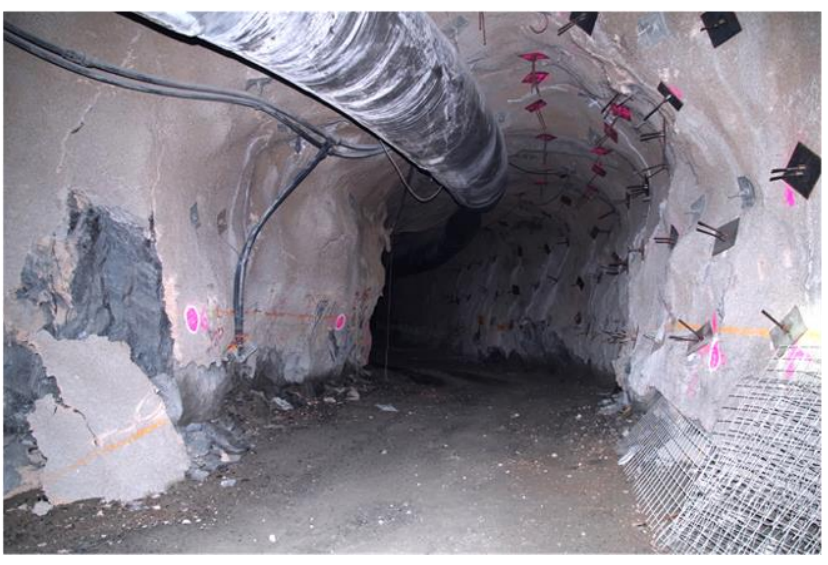

(a)

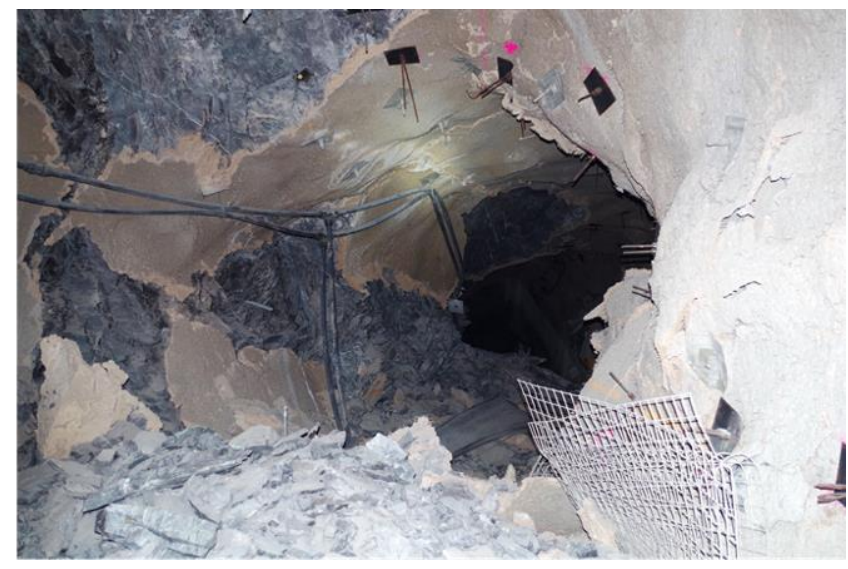

(b)

Figure 5 Initial squeezing and final profile before signing off in Level 4: (a) initial deterioration; and (b) final profile

\subsection{Monitoring}

Photo monitoring stations have been established in each of the affected areas; extensometer pins have been installed in Levels 4 and 5; survey monitoring of the drive profile was undertaken in Level 5. 


\subsubsection{Extensometer measurements}

Extensometer pins were installed in Levels 4 and 5 . These levels were selected because they were the most recently developed and therefore had undergone little deformation when changes in ore drive ground condition were first noticed and also had the longest life span, allowing larger amounts of data to be gathered. Pin locations in both Levels 4 and 5 were surveyed in enabling them to be replaced in exact locations if damaged/destroyed. This was exceptionally useful, particularly in Level 5 , which was an active development level when pins were initially installed and where a number of pins have been replaced due to ground movement/machinery damage.

Measurements in Level 4 were taken over a three month period before area became too damaged to enter without rehabilitation. During this time, the stoping front progressed to Level 3 and significant deformations were recorded around the Sandbar fold and Thresher fault zone, with the largest deformation of $0.5 \mathrm{~m}$ recorded at the north intersection between these two structures (Figure 6(a)). It is estimated that final deformation in this area was around $0.9 \mathrm{~m}$.

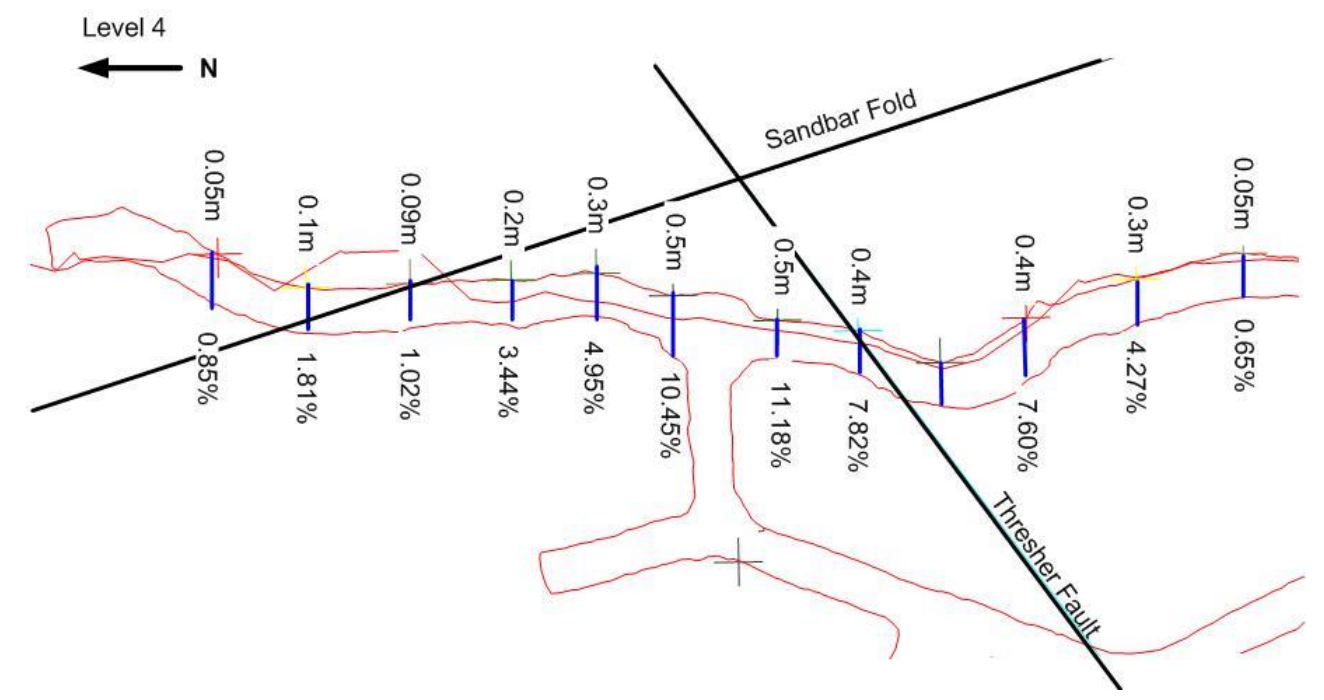

(a)

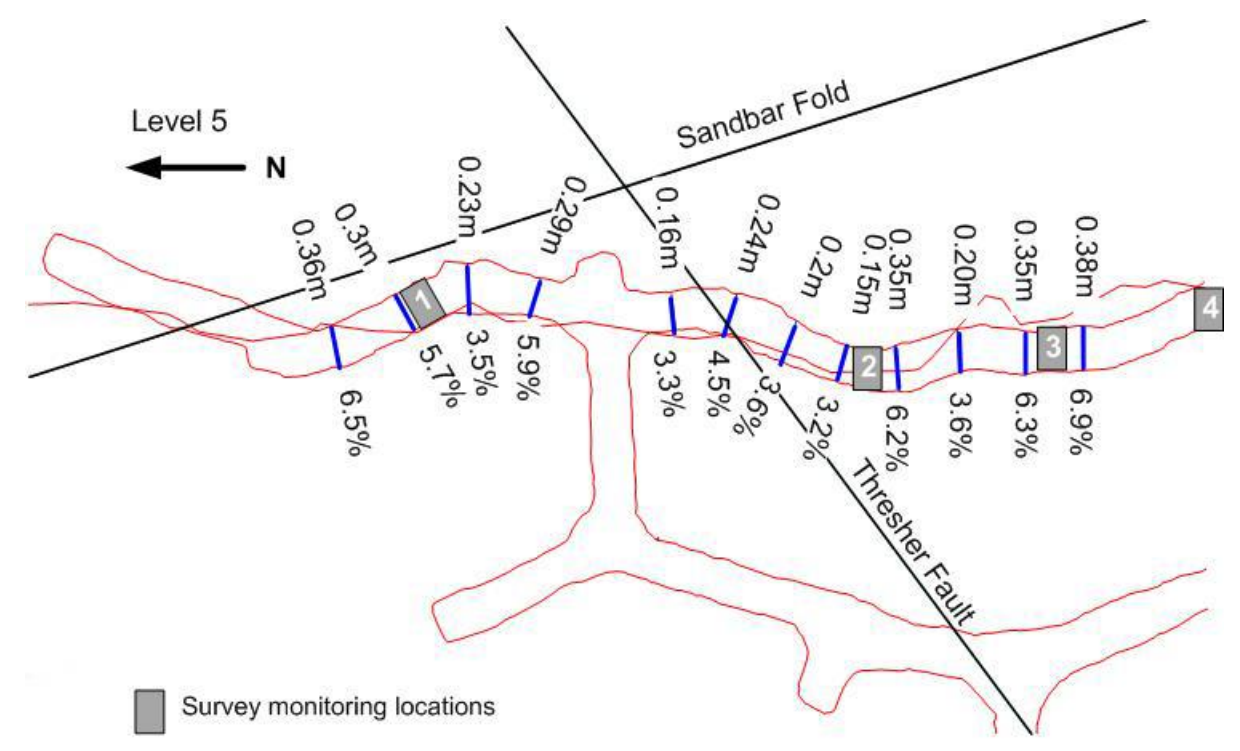

(b)

Figure 6 (a) extensometer locations, measured deformations and calculated strains, Level 4; and (b) extensometer and survey monitoring locations, measured deformations and calculated strain, Level 5 
Measurements in Level 5 have been taken over a 6-month period. As with Level 4, this drive showed significant deformation between the Sandbar fold and Thresher fault zone. However, the largest measured deformation is approximately $50 \mathrm{~m}$ from the Thresher zone (Figure 6(b)).

\subsubsection{Survey profile monitoring}

Survey profile monitoring was undertaken at four locations in Level 5 (Figure 6(b)) over a four month period with measurements being taken once every eight days. Measurements are on-going in location 1; locations 2, 3 and 4 were later designated as 'No Entry' until rehabilitation was undertaken.

Measured deformation from survey monitoring (Figure 7) is $\approx 120 \mathrm{~mm}$, this is considerably less than that measured using the extensometer, although, it should be noted that extensometer measurements began more than two months before survey monitoring and that deformation was on-going during this time span. Survey monitoring shows clear squeezing of the FW, corroborating extensometer measurements and observations, it also shows closure in backs and HW.

It has highlighted that adherence to design profile in Level 5 was poor. Intriguingly locations 3 and 4 , those with the most accurate profiles, appear to show more HW movement than locations 1 and 2. Very slightly more FW movement has also been recorded in location 4 compared to other locations. However, it is impossible to definitively say if the profile is affecting squeezing behaviour based on four monitoring locations. This may be an interesting area of further study.

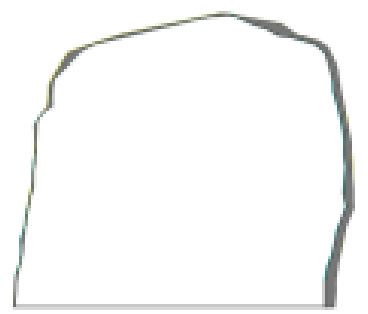

7a. Location 1

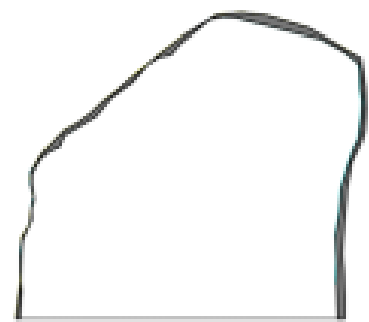

7c. Location 3

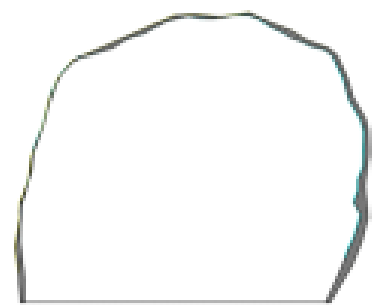

7b. Location 2

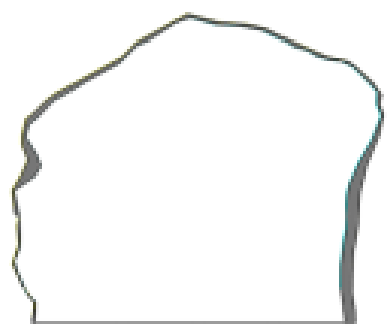

7d. Location 4

$\overline{1 m}$

Figure 7 Survey profile monitoring, Level 5

\subsubsection{Photo monitoring}

Photo monitoring stations were set up in each of the effected levels at strategic locations (Figure 8) and have proved to be a useful tool in tracking visible deformation and changes in profile. Photo monitoring has proved valuable in areas which have gone through initial deformation and been rehabilitated (Figures 9 and 10 ) in allowing each activity stage to be documented from set locations. It has also proved a useful visual tool when communicating changing conditions and hazards to underground personnel.

However, problems have been encountered in obtaining consistent picture quality and in maintaining exact locations as deterioration means wall markings have been obscured/destroyed. In order for photo monitoring to be more than a visual tool/tracking system, equipment capable of producing images for use 
in software, such as that available from Sirovision ${ }^{\mathrm{TM}}$, would be required; this option may be explored in future.

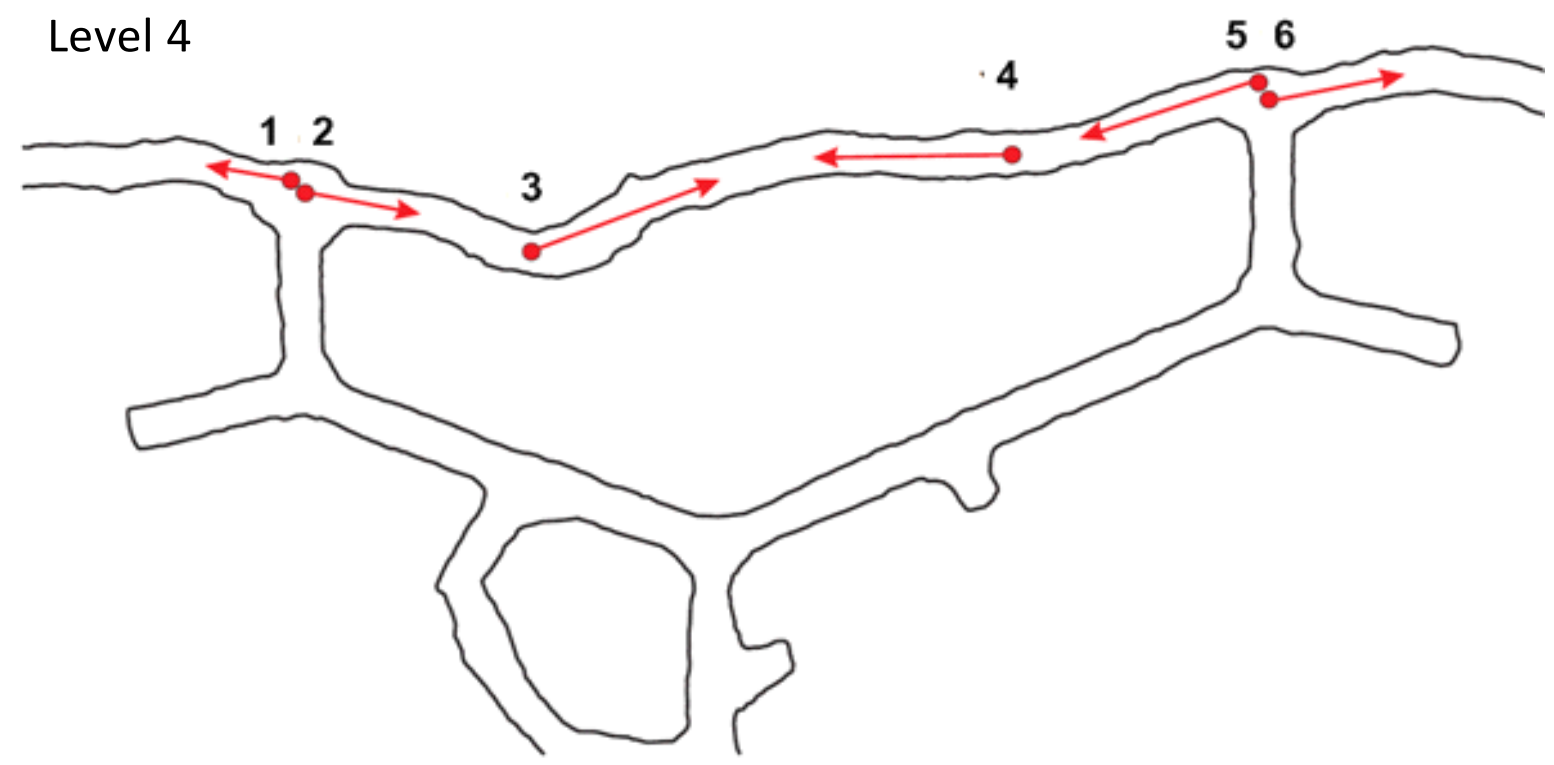

Figure 8 Illustrative photo monitoring locations

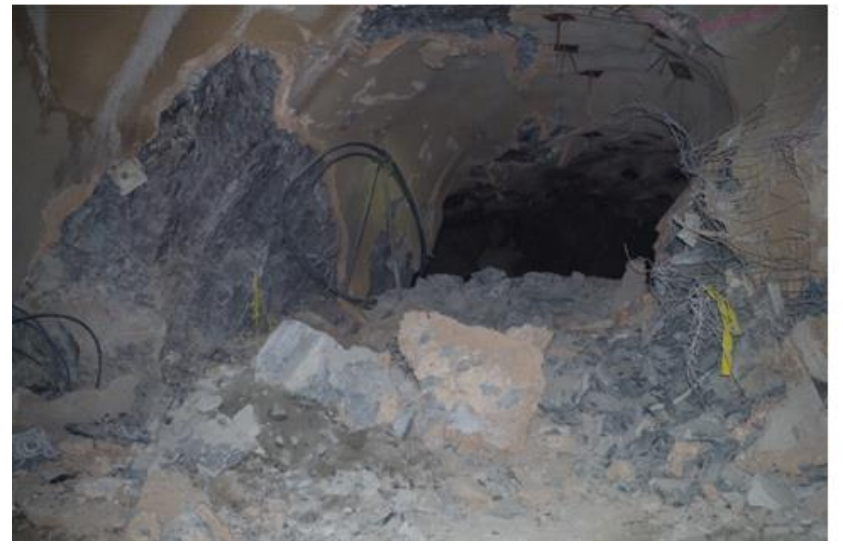

(a)

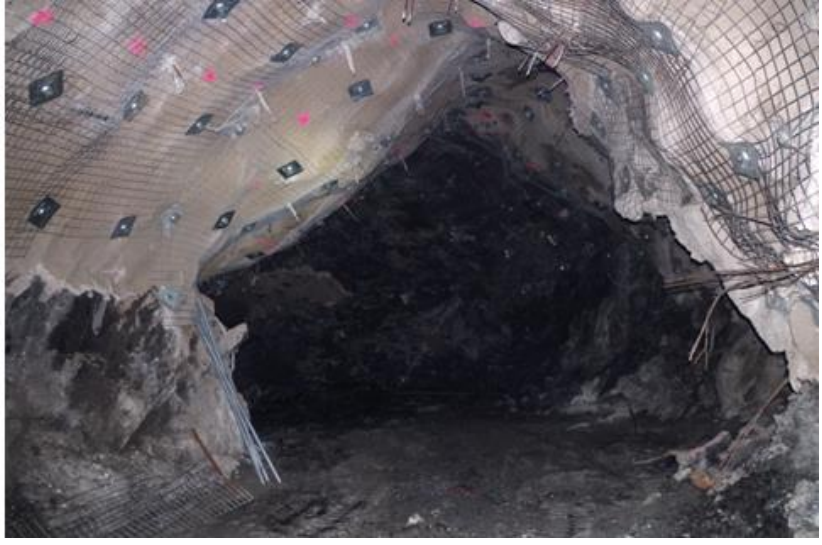

(b)

Figure 9 Level 3 north ore drive at peak deformation and after rehabilitation: (a) peak deformation; and (b) after rehabilitation 


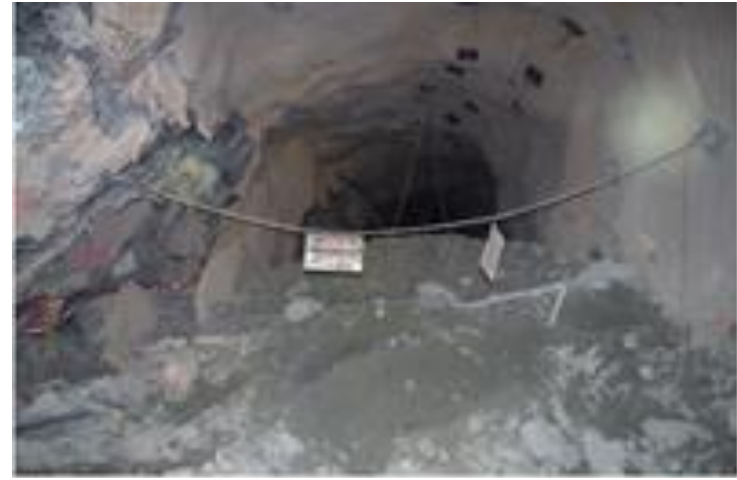

(a)

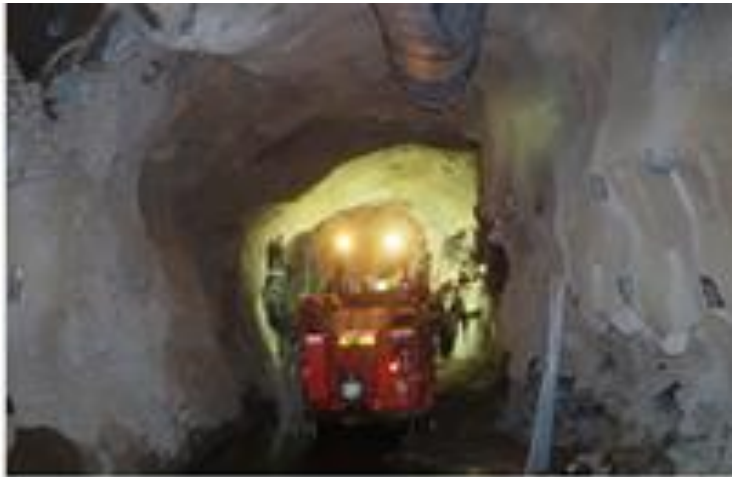

(b)

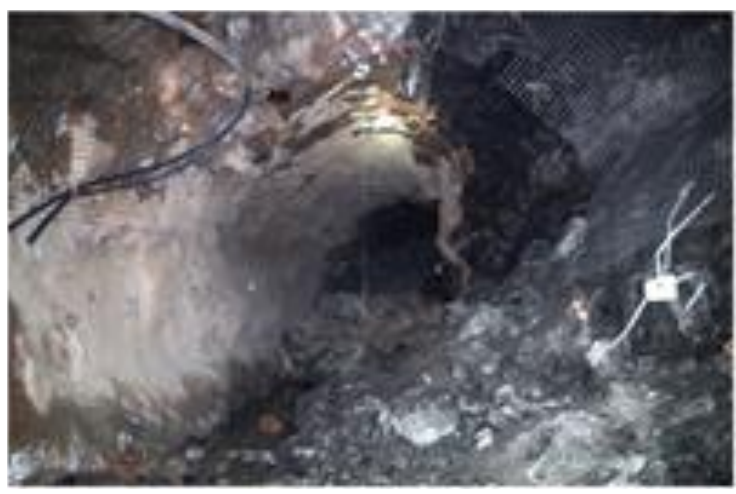

(c)

Figure 10 Level 3 deformation, first and second rehabilitation cycles: (a) stage 2 deformation; (b) first rehabilitation cycle; and (c) second rehabilitation cycle

\subsection{Testwork}

Historical information from nearby mines which exhibit squeezing ground indicates that alteration mineral type and abundance play a significant role in the levels of observed deformation. Based on this information samples of altered sandstone (SKgU) and ultramafic (SkU3) units were taken from grade control drilling in Level 5; samples were also obtained from levels above Level 1, which did not show significant squeezing, for comparison.

Chlorite, talc and amphibole were highlighted as key minerals for potentially affecting squeezing behaviour and broadly speaking amounts of these minerals are similar in squeezing and non-squeezing levels (Table 1). Slightly higher amounts of chlorite and talc, both known to adversely affect stability, are present in non-squeezing levels, which is unexpected. Higher levels of amphibole are present in the squeezing levels.

Amphibole is regarded as being integrally linked with the mineralisation process at Waroonga and as possibly providing a proxy for fluid flow locations in the system, i.e. indicating areas of increased alteration (site geology department, personal communication). Increased alteration may result in a reduction in rock quality/condition making areas more likely to squeeze. However, at this point it remains unclear what effect, if any, higher levels of amphibole minerals are having in squeezing areas. This is due in part to the small sample size and additional testwork has been commissioned.

It should also be noted that samples from non-squeezing levels were taken from historical ore definition programs; every effort was made to source samples near field to non-squeezing ore drives but it cannot be guaranteed and samples may be sourced from further into the FW than was actually developed. 
Table 1 Mass percent present

\begin{tabular}{ccccc}
\hline Mineral & Non-squeezing \#1 & Non-squeezing \#2 & Level $\mathbf{5}$ \#1 & Level $\mathbf{5}$ \#2 \\
\hline Chlorite & 30 & 25 & 9 & 24 \\
Talc & 10 & 13 & 4 & 3 \\
Amphibole & 21 & 48 & 45 & 58 \\
\hline
\end{tabular}

\section{$4 \quad$ Hard rock squeezing ground index}

The hard rock squeezing ground index, developed at LaRonde Mine (Mercier-Langevin \& Wilson 2013; Hadjigeorgiou et al. 2013), was used to predict squeezing behaviour when deformation was first observed and to categorise levels of deformation experienced in the lower five levels.

When lower bound ultramafic strength (SkU3) was used and taking into account increased stress with depth Levels 1-5 were all predicted to experience severe to very severe squeezing conditions (Figure 11); all parameters (Table 2) remained constant across levels except principal stress which increased by $\approx 1 \mathrm{MPa}$ per level. This can be directly correlated to percentage strain, calculated after Hadjigeorgiou et al. (2013), which showed that Levels 4 and 5 were experiencing, on average, very severe levels of squeezing, with two locations in Level 4 falling into the extreme category.

The highest percentage strain in Level 4 was measured at Pin 7, and at $11.17 \%$ places this area in the extreme squeezing category of the hard rock squeezing ground index (Mercier-Langevin \& Hadjigeorgiou 2011; Mercier-Langevin \& Wilson 2013). The largest strain calculated so far in Level 5 is $6.88 \%$ at Pin 12 (Figure 6) placing this area in the very severe squeezing category; it should be noted that further deformation is expected in Level 5 as has already occurred in Level 4.

The extreme squeezing recorded in Level 4 indicates that ultramafic (SkU3) strength may be lower than believed or that bedding may be more closely spaced. Testwork has been commissioned to investigate ultramafic strength and a mapping/logging program will be initiated to quantify joint spacing in squeezing levels.

Table 2 Hard rock squeezing ground index parameters

\begin{tabular}{cccccc}
\hline Level & \multicolumn{3}{c}{ UCS (MPa) } & \multirow{2}{*}{$\begin{array}{c}\text { Stress }\left(\sigma_{1}\right) \\
(\mathrm{MPa})\end{array}$} & $\begin{array}{c}\text { Foliation spacing } \\
(\mathbf{m m})\end{array}$ \\
\cline { 2 - 4 } & HW & Best FW & Worst FW & & (M) \\
\hline Level 2 & 160 & 40 & 30 & 64 & $10-100$ \\
\hline
\end{tabular}



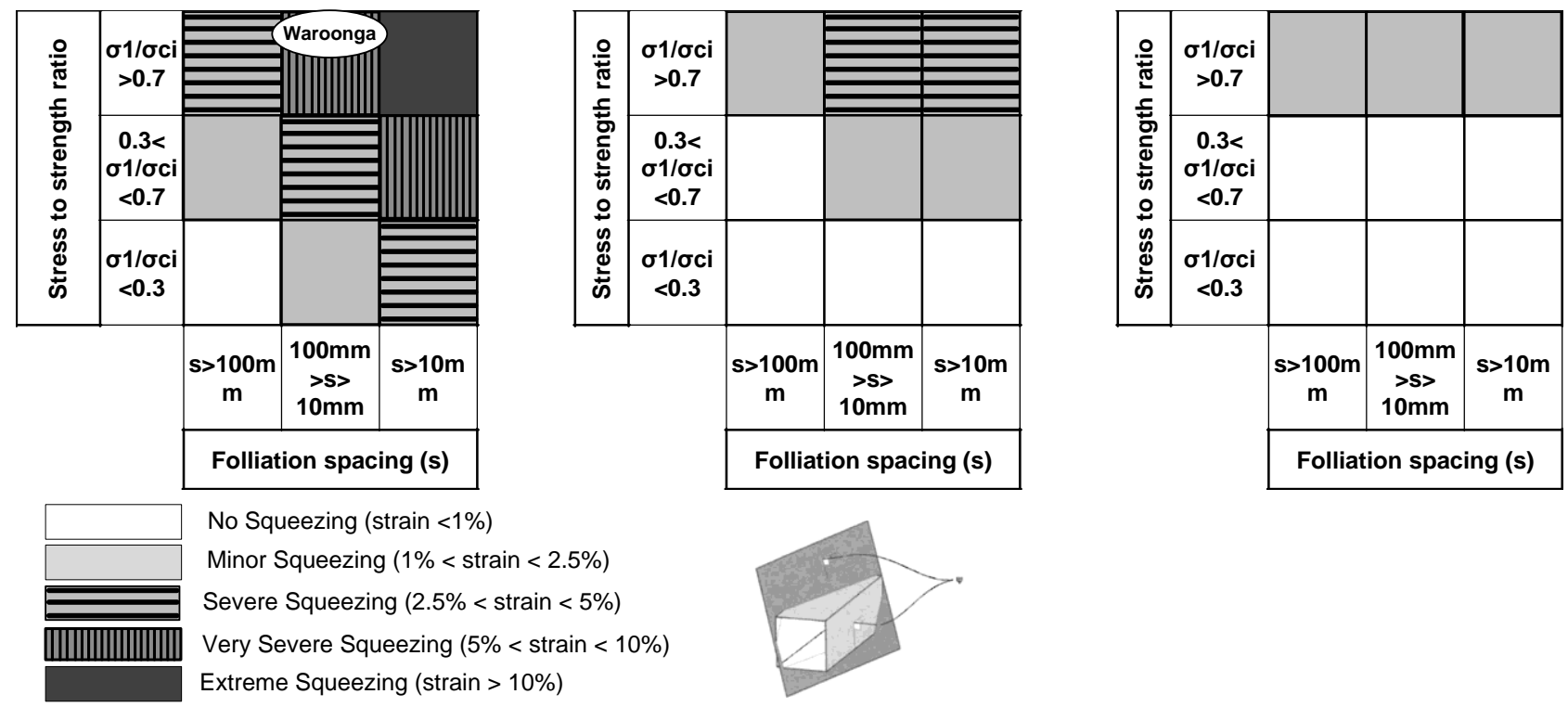

Figure 11 Squeezing matrices for different angles of interception, after Mercier-Langevin and Hadjigeorgiou (2011) and Mercier-Langevin and Wilson (2013), with squeezing prediction for Waroonga Lode 1

\section{$5 \quad$ Two-dimensional finite element modelling}

2D Finite element modelling, using Phase2, was undertaken for the ore drive design profile (shanty profile) and for an arched profile in Level 5, i.e. 1,260 m below surface. An arched profile was modelled since results of survey profile monitoring indicated that many areas of the Level 5 ore drive were mined to an arched profile, rather than the shanty design profile, and that these areas may be exhibiting different squeezing behaviour.

Four materials (Table 3 ) were modelled reflecting the different rock units intersecting/in close proximity to Lode 1 ore drives. Rock properties such as Young's modulus, Poisson's ratio and UCS were taken from site GCMP; lower bound UCS values were used as this gave a better fit with conditions observed underground. geological strength index (GSI) was determined from site logging databases and used to determine mi. Sandstone and ore were modelled as elastic since squeezing is not generally observed in these units; ultramafic and altered sandstone were modelled as plastic.

Joint sets were added based on those identified by onsite data collection methods. Only those in sandstone and ore were given properties (Table 4). Properties were assigned based on back analysis of observed conditions/ failure mechanisms underground. Support was also added in the form of fully bonded bolts and plain strand cable bolts to match as closely as possible the ground support standard (Figure 2).

Results of shanty profile modelling (Figure 12(a)) show potential for up to $600 \mathrm{~mm}$ of squeezing, which corresponds well with observed conditions in Levels 4 and 5 , this model also showed potential for sliding from HW joints; also observed underground. The model did not capture significant deformation in HW shoulder and backs. Interestingly results of arched profile modelling (Figure 12(b)) shows less deformation in FW, with just $300 \mathrm{~mm}$ predicted with this profile; this appears to corroborate initial analysis of survey profile monitoring. 


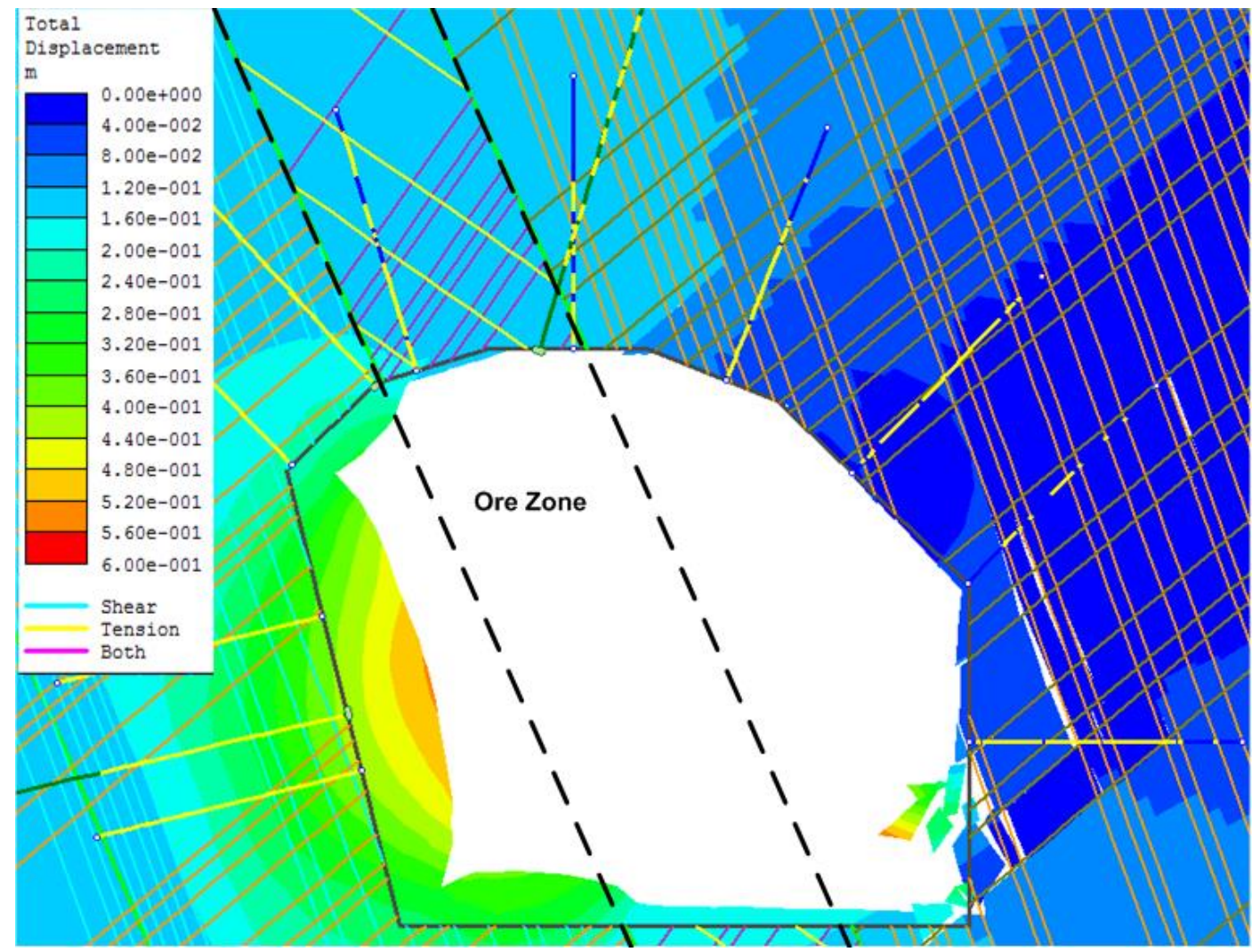

(a)

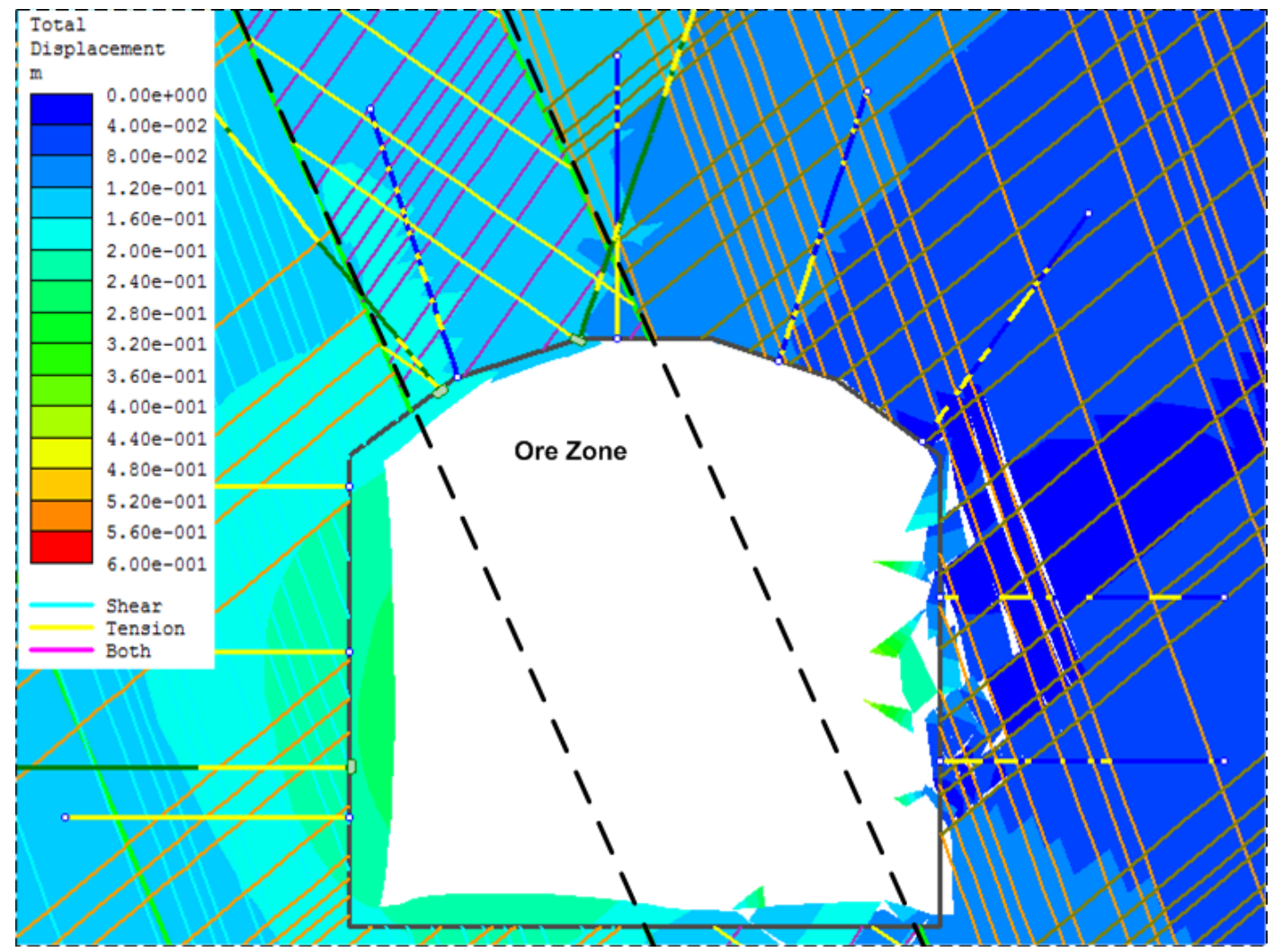

(b)

Figure 12 Total deformation predictions from 2D finite element modelling of Level 5: (a) shanty drive profile; and (b) arched drive profile 
Table 3 Phase2 material input parameters

\begin{tabular}{|c|c|c|c|c|}
\hline & Material 1 & Material 2 & Material 3 & Material 4 \\
\hline Rock type & $\begin{array}{l}\text { Sandstone } \\
\text { (SKg) }\end{array}$ & Ore & $\begin{array}{l}\text { Ultramafic } \\
\text { (SKcU3) }\end{array}$ & $\begin{array}{l}\text { Altered sandstone } \\
\text { (SKgU) }\end{array}$ \\
\hline Criterion & $\begin{array}{c}\text { Generalised } \\
\text { Hoek-Brown } \\
\text { (elastic) }\end{array}$ & $\begin{array}{c}\text { Generalised } \\
\text { Hoek-Brown } \\
\text { (elastic) }\end{array}$ & $\begin{array}{c}\text { Generalised } \\
\text { Hoek-Brown } \\
\text { (elastic) }\end{array}$ & $\begin{array}{l}\text { Generalised } \\
\text { Hoek-Brown } \\
\text { (plastic) }\end{array}$ \\
\hline $\mathrm{E}(\mathrm{MPa})$ & 50,000 & 30,000 & 25,000 & 30,000 \\
\hline $\mathbf{v}$ & 0.25 & 0.25 & 0.3 & 0.3 \\
\hline UCS (MPa) & 160 & 80 & 25 & 40 \\
\hline GSI & 71 & 60 & 35 & 40 \\
\hline mi & 19 & 19 & 7 & 10 \\
\hline Df & 0 & 0 & 0 & 0 \\
\hline
\end{tabular}

Table 4 Phase2 joint input parameters

\begin{tabular}{|c|c|c|c|c|}
\hline & $\begin{array}{c}\text { Joint set } 1 \\
\text { (sandstone) }\end{array}$ & $\begin{array}{c}\text { Joint set } 2 \\
\text { (sandstone) }\end{array}$ & $\begin{array}{l}\text { Joint set } 3 \\
\text { (ore) }\end{array}$ & $\begin{array}{l}\text { Joint set } 4 \\
\text { (ore) }\end{array}$ \\
\hline $\operatorname{Dip}\left({ }^{\circ}\right)$ & -70 & 40 & 55 & -35 \\
\hline Mean spacing (m) & 0.1 & 0.5 & 0.3 & 1 \\
\hline Distribution & Lognormal & Lognormal & Lognormal & Lognormal \\
\hline Criterion & Mohr-Coulomb & Mohr-Coulomb & Mohr-Coulomb & Mohr-Coulomb \\
\hline$\sigma_{t}(\mathrm{MPa})$ & 0.5 & 0.5 & 0.75 & 0.75 \\
\hline $\mathrm{C}(\mathrm{MPa})$ & 0.25 & 0.25 & 0.5 & 0.5 \\
\hline$\phi\left({ }^{\circ}\right)$ & 35 & 35 & 35 & 35 \\
\hline
\end{tabular}

\section{Controls/strategies}

Based on observations, monitoring and modelling a number of controls have been put in place to ensure that safety of personnel is not compromised and that production requirements of the operation are impacted as little as possible.

It was determined early on that any rehabilitation required in non-production areas would be completed on a just-in-time basis, before stoping, in an effort to limit the number of rehabilitation cycles. Therefore, areas where rehabilitation would be required for personnel entry were signed off.

\subsection{Signing off levels}

Areas would initially be designated as 'No Unauthorised Entry' at the discretion of onsite geotechnical engineers or underground/mine managers when any/all of the below conditions were met:

- Deformation, measured by extensometer or survey pick up, was between 200 and $300 \mathrm{~mm}$. $300 \mathrm{~mm}$ is the commonly accepted point at which ground support will no longer be completely effective. 
- Depth of broken ground in intersection backs was up to $1.5 \mathrm{~m}$ as determined by jumbo probing, i.e. beyond this point, $2.4 \mathrm{~m}$ rockbolts would not have enough embedment length to support dead weight.

- Up to $20 \%$ of primary ground support, by eye, was failed/in need of rehabilitation.

Areas would be designated as 'No Entry' when more than $20 \%$ of primary ground support was compromised, broken ground in backs was greater than $1.5 \mathrm{~m}$ and deformation was more than $300 \mathrm{~mm}$. Signing levels off initially as 'No Unauthorised Entry' meant data collection and inspections could continue and allowed a better understanding of deformation/deterioration stages to be gained.

\subsection{Rehabilitation}

Once it became clear that ongoing, and significant, rehabilitation would be required in Levels 1-5 a dedicated rehabilitation Jumbo was brought to site ensuring that work could be completed without sacrificing development elsewhere.

When initial signs of squeezing were observed in Level 1 stoping had already begun, mesh was installed over cracking FC in backs/shoulder of drive. At this time deformation was also observed in Levels 2, 3, 4 and 5, and reinforcement in FW and backs was increased in the form of additional cable bolts. Recognising that FC is too stiff to adequately support squeezing ground and in an effort to limit rehabilitation cycles additional mesh was also installed in shoulders/backs of Levels 4 and 5 creating an initially stiff liner, with ductile capacity once FC has cracked (Hadjigeorgiou et al. 2013). Installing mesh over FC has increased length of time ore drives are useable without rehabilitation, but severe/extreme squeezing conditions have meant that further rehabilitation cycles are necessary.

As ground condition continued to deteriorate around stoping front drives were scaled/stripped and support returned to site standard. However, as additional work was required in Levels 1, 2 and 3 after each stoping panel rehabilitation strategy was altered to optimise use of available assets while maintaining required Factor of Safety (FS).

Intersections requiring rehabilitation have been scaled/stripped to form an exaggerated dome shape and heavily supported with FC, cable bolts and mesh straps in an effort, which has so far been successful, to complete only one rehabilitation cycle in these locations.

\subsubsection{Rehabilitation support standards}

As mentioned above during rehabilitation ore drives were initially re-supported to site standard. However, as multiple rehabilitation cycles started to become required strategy was altered. It was decided to use mesh and $2.4 \mathrm{~m}$ friction stabilisers as primary support with damaged cables in re-installed as per additional cable plans.

Kinematic analysis, using Unwedge, of joint sets present in HW, ore zone and FW showed that $2.4 \mathrm{~m}$ friction stabilisers, combined with cable bolts, would provide a FS of 1.8 and 1.7, in the ore zone and HW respectively, for wedges most likely to cause failure (Figure 13). FS is likely higher in actuality since interface between HW and ore zone will truncate the maximum size of wedges formed. Given this, and given that the site required FS for ground support is 1.5, the calculated FS of 1.7 and 1.8 were considered as acceptable. 


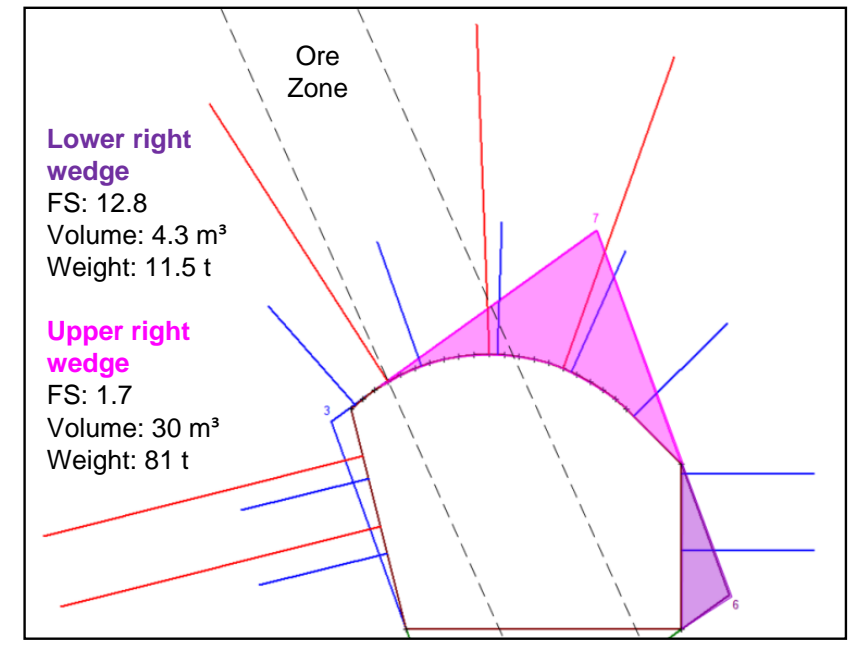

(a)

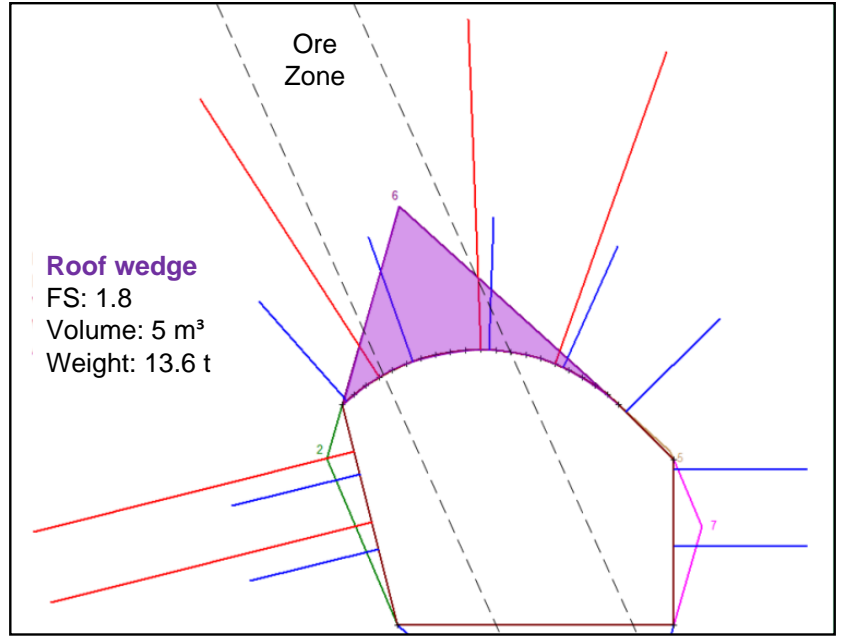

(b)

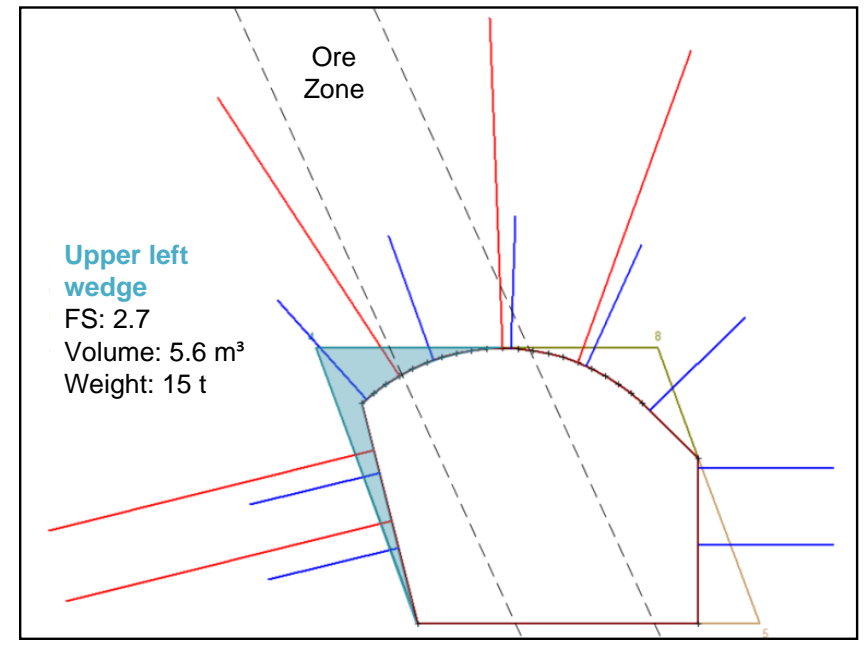

(c)

Figure 13 Kinematic analysis of possible HW, FW and ore zone wedges with planned rehabilitation support elements: (a) HW joint sets; (b) ore zone joint sets; and (c) FW joint sets

\subsubsection{Rehabilitation planning}

In order to ensure that rehabilitation work was completed with as little impact to the stoping timetable as possible, scheduling of work was undertaken as part of the quarterly, monthly and weekly planning process. For longer-term planning, i.e. quarterly and monthly, this involved discussions with planning engineers to determine a rough scope of works and timescale for rehabilitation in each of the affected areas so that stoping could be adjusted.

For the purposes of weekly (short-term) planning, three main controls were put in place:

- Pre-planning inspections; before planning meetings are undertaken each area where production activities are expected to occur in the coming week is inspected by geotechnical engineers, production engineers and site foremen. This ensures that each of the relevant personnel understands what is required in each area and how long it will take.

- Specific rehabilitation planning; after the pre-planning inspections have been completed discussions of requirements for the coming week are undertaken and planned on a shift by shift basis with required assets e.g. service crew, jumbo, spraymec, cabletec etc. specified. 
- Rehabilitation section in the weekly planning meeting; a section detailing assets and timings for rehabilitation has been included in the weekly plan. Here rehabilitation requirements can be easily compared to other works e.g. development etc. and thus potential conflicts identified and mitigated. This process also allows for clear rehabilitation targets and priorities to be set and tracked on a weekly basis.

Rehabilitation progress/compliance to plan tracking is undertaken on a daily basis and has been incorporated into the daily production meeting.

\subsection{Future controls}

Going forward more work will be done on underlying causes and long-term controls for squeezing ground at the Waroonga underground complex. This will included further study on the effect of profile on squeezing, with ore drive profile trials planned for the near future; new ore drive development will be undertaken on a just-in-time basis. Ground support trials are also planned with support elements being varied according to potential for squeezing. Changes to extraction sequence will also be explored. The most promising of mitigating strategies will be taken forward after analysis and trials have been completed.

Additional testwork has been commissioned to gather more mineralogy and strength data. Line mapping of all ore drives will also be undertaken. The Zeb1, a handheld scanner, has been brought to site and will be used in place of survey monitoring to build a complete picture of ore drive changes with time. 3D discontinuum modelling of the operation has also been commissioned.

\section{Conclusion}

Squeezing ground is very severe to extreme in the lowest five levels of Lode 1 at the Waroonga underground complex. When combined with lower bound FW material properties, it is certainly influenced by induced stress at current mining depths. It may also be affected by changes to rock mass properties, i.e. changes to alteration mineral type and abundance, changes in joint spacing and lower strengths. Observed squeezing may also be exacerbated by drive profile. Work to identify the root causes of squeezing conditions is ongoing.

Fibrecrete is too stiff to support ground for current drive life where it is the only surface support, although it performs relatively well with mesh addition. Nonetheless, current and future rehabilitation will be completed using mesh wherever practicable. Trials will be undertaken in the near future to assess suitability of different support systems, when combined with just-in-time development.

Signing off areas where significant deformation has been observed/recorded and instituting a policy of just-in-time rehabilitation has reduced the required number of rehabilitation cycles. Modifying ground support in rehabilitation areas has enabled a quicker turnaround without compromising FS. Short-term planning and daily tracking has proved to be a key tool in managing rehabilitation requirements.

\section{References}

Hadjigeorgiou, J, Karampinos, E, Turcotte, P \& Mercier-Langevin, F 2013, 'Assessment of the influence of drift orientation on observed levels of squeezing in hard rock mines', in Y Potvin (ed.), Proceedings of the Seventh International Symposium on Ground Support in Mining and Underground Construction (Ground Support 2013), Australian Centre for Geomechanics, Perth, pp. 109-118.

Mercier-Langevin, F \& Hadjigeorgiou, J 2011, 'Towards a better understanding of squeezing potential in hard rock mines', Mining Technology Journal, vol. 120, no. 1, pp. 36-44.

Mercier-Langvin, F \& Wilson, D 2013, 'Lapa Mine - ground control practices in extreme squeezing ground', in Y Potvin (ed.), Proceedings of the Seventh International Symposium on Ground Support in Mining and Underground Construction (Ground Support 2013), Australian Centre for Geomechanics, Perth, pp. 119-133.

Potvin, Y \& Hadjigeorgiou, J 2008, 'Ground support strategies to control large deformations in mining excavations, Journal of the Southern African Institute of Mining and Metallurgy, vol. 108, pp. 393-400. 